\title{
Razonando Cuestiones de principios (Respuesta a mis críticos)*
}

\author{
Alfonso Ruiz Miguel \\ Universidad Autónoma de Madrid \\ ORCID ID 0000-0002-6306-7291 \\ alfonso.ruiz@uam.es
}

\section{Cita recomendada:}

Ruiz Miguel, A. (2021). Razonando «Cuestiones de principios» (Respuesta a mis críticos). Eunomía. Revista en Cultura de la Legalidad, 20, pp. 463-486.

doi: https://doi.org/10.20318/eunomia.2021.6090

Recibido / received: 08/03/2021

\begin{abstract}
«Las personas de buen juicio, según luego he podido apreciar, rara vez caen en el vicio de discutir, salvo los abogados, los universitarios o los que se han criado en Edimburgo». Benjamin Franklin, Autobiografía.
\end{abstract}

El mejor homenaje a un libro recién publicado es tenerlo en cuenta. Mi agradecimiento por ello a los cinco amigos y colegas que con gran generosidad con su tiempo han asumido la tarea de leer y responder a la para mí tan sorprendente como grata iniciativa de José María Sauca de organizar este debate en Eunomía. Como sugiere Francisco Laporta al final de su también generoso prólogo, no está clara la unidad de contenidos del libro, y me temo que esa misma diversidad puede trasladarse a este debate. Ciertamente, todos los temas allí y aquí tocados, como los mismos participantes, tienen o tenemos el aire de familia de una larga y estrecha relación con la filosofía del Derecho, pero tampoco tengo claro que esa materia, un poco en tierra de nadie entre dos saberes muy distintos y otro poco dividida entre temas y enfoques diversos, tenga la unidad de fondo que tienden a exigir los pensadores erizo. Lo que como inevitable zorro me preocuparía más, en cambio, es que más allá de la probable coherencia de método, que Paco Laporta caracteriza como «voluntad de argumento»

\footnotetext{
* Indicaré entre paréntesis en el texto las citas de mi libro Cuestiones de principios, identificado por el año 2020 seguido de la página citada. Las referencias entre paréntesis en el texto sin indicación de autor ni año lo serán a las páginas en este mismo número de Eunomía de las contribuciones a este debate, que serán fáciles de identificar contextualmente por el apartado en el que se encuentran. En el resto de referencias entre paréntesis en el texto se indicará la correspondiente autoría, año y página(s).
} 
(2020, p. 19), en el libro y en el modo de abordar sus temas se echara de menos alguna severa incoherencia en los principios que alientan detrás de las cuestiones debatidas. Creo que este debate es una oportunidad de ponerlo a prueba, es decir, de reflexionar no solo sobre algunas cuestiones más o menos concretas sino también sobre la coherencia de mis convicciones últimas. $Y$ ese es otro motivo más de agradecimiento.

1. La cuestión constitucional de la laicidad: de la deliberación pública al agnosticismo (Rodolfo Vázquez)

El buen amigo Rodolfo Vázquez propone volver a un tema sobre el que hemos ya debatido anteriormente: la laicidad. En su amplia reflexión, Rodolfo aborda cuatro aspectos diferentes, tres de los cuales hemos debatido previamente. En uno de ellos, el del último apartado, dedicado al papel de la religión en la deliberación pública, reafirma y añade razones en una línea en la que ya habíamos coincidido de manera muy sustancial y en la que mi acuerdo continúa sin fisuras. Ambos hemos compartido la idea de Rawls de que en la esfera pública, incluido en ella el debate político no institucional, deben ser mantenidos al margen los argumentos idiosincrásicamente religiosos ( $\mathrm{y}$ en realidad, más en general, argumentos de carácter idiosincrásico, es decir, argumentos que solo puedan ser válidos por quienes comparten creencias que ellos mismos deben considerar propias y exclusivas de una posición no imponible a los demás). Frente a la mayor tolerancia de Habermas y otros autores ante la introducción de los argumentos religiosos en el debate público, la razón fundamental de nuestra restricción es que el resultado de tal debate concluye en último término, según es característico de la política, en imposiciones apoyadas en la coacción.

Con todo, más allá del fuerte acuerdo, últimamente me viene asaltando alguna duda sobre nuestra común preocupación y el mejor modo de abordarla, lo que me anima a introducir una precisión sobre un punto. Para llegar a la precisión quiero ilustrar mi duda con un tema de gran actualidad en España, donde está a punto de ser aprobada una ley que regula la eutanasia a solicitud de personas con una "enfermedad grave e incurable o un padecimiento grave, crónico e imposibilitante», una cuestión que tiene con ver con los tres primeros capítulos del libro. Pues bien, en la oposición precedente y coetánea a la ley están clamorosamente ausentes los argumentos directamente religiosos. Incluso la Conferencia Episcopal Española, la única alusión expresamente religiosa que se ha permitido en una reciente Nota sobre la ley ha sido convocar a los católicos españoles a una jornada de ayuno y oración «para pedir al Señor que inspire leyes que respeten y promuevan el cuidado de la vida humana» (Conferencia Episcopal Española, 2020). Si esto es así -y con mayor razón si además fuera cierto que, en último término, solo la creencia en la vida como don divino indisponible para los humanos puede justificar una negación absoluta de la eutanasia ${ }^{1}$-, tal vez lo que una posición laica o liberal debería comenzar a reclamar no es tanto la evitación de los argumentos religiosos en el debate previo a las decisiones, sino una rigurosa honestidad en su formulación. Y para ello sería necesario no cerrar el diálogo a las razones religiosas, también para permitir desvelar sus conexiones con razones solo aparentemente universalizables. Y llego ya a la precisión: debido a la ambigüedad proceso-producto de la idea de deliberación, creo que tanto Rodolfo como yo mismo no hemos dejado suficientemente claro que una cosa es excluir las razones idiosincrásicas de la deliberación pública como producto,

\footnotetext{
${ }^{1}$ Cf. últimamente en tal sentido, Flores d'Arcais (2019, pp. 109 ss.). Pongo mi frase en condicional porque tal vez las razones kantianas contra el suicidio, desde luego absolutistas, pudieran ser independientes de alguna inspiración religiosa. En todo caso, un ejemplo quizá más claro de inevitable contaminación religiosa de una razón moral es la atribución del valor de persona al embrión humano por la creencia en la inspiración del alma desde el momento de la concepción.
} 
que es lo decisivo, y otra excluir la apelación a esas razones en el proceso de la deliberación, una apelación que no se debería obstaculizar si lo que se pretende es someter las creencias a un escrutinio de razonabilidad. Sé que eso supone asumir el riesgo de que el resultado de la deliberación sea incorrecto, pero se trata de un riesgo que se debe asumir en todo caso, siempre en la confianza milliana de que la libertad terminará por hacer prevalecer las mejores razones.

El segundo tema ya debatido previamente viene de la insistencia de Rodolfo Vázquez en diferenciar entre neutralidad e imparcialidad. Mientras yo he tendido a identificar ambos términos a lo largo de mis escritos, Rodolfo sigue creyendo importante distinguir entre «neutralidad», entendida como abstención pasiva, e «imparcialidad», entendida como actividad protectora de la igualdad de derechos, añadiendo ahora que una y otra corresponderían a dos concepciones o vertientes distintas del liberalismo: la primera a la concepción libertaria, de mero laissez faire y por ende de convalidación del statu quo, mientras la segunda a la concepción igualitaria, comprometida con una visión del Estado como responsable de deberes positivos para la protección de los derechos básicos. Nuestro acuerdo en cuanto al fondo de este asunto no puede ser mayor, como el propio Vázquez anticipa tras recordar cómo yo ya había precisado que mi visión del papel del Estado exige no solo adoptar la defensa activa del derecho a la igual libertad en materia religiosa sino también el apoyo abierto a la ciencia frente a otras formas de entender el mundo.

Ahora puedo añadir en la misma línea que, como lo muestra el capítulo 4 del libro, sobre la Educación para la ciudadanía, también comparto la idea de la importancia de llevar a la escuela la transmisión de los principios inspiradores de la democracia liberal, dejando desde luego la educación religiosa en el ámbito familiar y en la mera opcionalidad escolar. Nuestro desacuerdo es $-\mathrm{y}$ seguirá siendo, en la medida en que preveo que me será difícil ser infiel a mi convención- puramente terminológico (o "semántico», como Rodolfo Vázquez prefiere decir, según otra convención lingüística): al fin y al cabo, no solo es que neutralidad como imparcialidad tengan una etimología latina que alude a un mismo significado (ne-uter, ni de uno u otro; ne-pars, no de una parte), o que la expresión canónica, tradicional y absolutamente generalizada en la discusión anglosajona $-\mathrm{y}$, por tanto, ay, en la nuestra-, sea la de la neutralidad liberal $^{2}$, sino que nada impide, al contrario, reconocer que una auténtica neutralidad o imparcialidad en materia religiosa exija tomar partido en favor de algunos derechos básicos. Quizá uno de los milagros de la comunicación humana es cómo a pesar de las palabras y de los juegos de palabras podemos seguir entendiéndonos y estar de acuerdo.

Un tercer tema también recurrente en nuestro diálogo precedente afecta a la cuestión del laicismo como posición diferente de la laicidad liberal que el Estado, pero no los ciudadanos, debe asumir como posición neutral (o imparcial). Rodolfo Vázquez acepta sin objeciones mi defensa de tal forma de laicidad como un término medio entre cualquier forma de confesionalismo, y especialmente del encubierto bajo la denominación de la «laicidad positiva», y esa otra forma de confesionalismo a la inversa que es el laicismo militante o antirreligioso. Sin impugnar la pertinencia de esta última categoría ${ }^{3}$, Vázquez objeta su aplicabilidad al caso mexicano. En realidad, desde la primera vez que lo propuse, me cuidé de advertir que ese caso, al igual que el francés, no era una manifestación típica y completa del modelo laicista en cuanto tal, al modo integral en que lo han sido Estados beligerantemente ateos como el soviético o la China maoísta, sino solo una mera ejemplificación de algunas

\footnotetext{
2 Por citar algunos libros recientes que recogen esa más larga tradición, vid. Zellentin (2012), Merrill y Weinstock (2014) y Leni (2016).

${ }^{3}$ La ha impugnado, en cambio, Atienza (2019), al que respondo en Ruiz Miguel (2021).
} 
manifestaciones específicas de laicismo estatal. Rodolfo sigue considerando inadecuada tal ejemplificación y defiende que los dos tipos de regulaciones que yo señalé como no neutrales en realidad pueden justificarse en términos perfectamente liberales. Se trata de la exclusión de los derechos de asociación política y de sufragio pasivo a los ministros o sacerdotes de cualquier culto (y no solo a los «prelados», al menos entendidos como superiores jerárquicos de un culto), así como de la prohibición, extendida también a las iglesias, de poseer o administrar, incluso por persona interpuesta, cualquier medio de comunicación de masas.

Yo avancé en su momento serias reservas a estas restricciones de derechos políticos básicos, que me pareció que carecían de justificación suficiente en su aplicación a miembros de la sociedad civil (a diferencia, de la limitación habitual en muchos países del sufragio pasivo a algunos funcionarios, como jueces o militares en activo) y que no tienen comparación ni siquiera con algunas legislaciones europeas, como la alemana, que siguen una concepción de "democracia militante» que convalida la posibilidad de prohibir partidos antidemocráticos o relacionados con actividades violentas (Ruiz Miguel, 2010, pp. 83 ss.). El amigo Vázquez aduce ahora en su réplica dos argumentos diferentes: por una parte, como razón más general, la necesidad de excluir el "adoctrinamiento político o religioso» del espacio público institucional, que en México habría impedido históricamente la injerencia de las iglesias en el Estado y, en especial, el contubernio con fuerzas armadas violadoras de los derechos humanos (pp. 421-422); por otra parte, respecto de la prohibición del control de medios de comunicación, la razón más específica de que se trata de limitar los derechos de instituciones y no de los individuos que profesan una determinada fe.

No estoy seguro de poder aceptar esas razones. Por comenzar por la segunda, reconozco que los derechos no tienen la misma fuerza justificativa para los individuos que para las personas jurídicas, pues la titularidad de los derechos de estas últimas se justifica derivada e instrumentalmente de las necesidades, intereses y fines de los individuos que las componen. Eso aceptado, sin embargo, en el caso de los medios de comunicación, como en el de las instituciones educativas religiosas, no veo razones especiales para romper jurídicamente aquella derivación instrumental hasta negar al colectivo los derechos que sí se reconocen a los individuos. Por su parte, en cuanto a la razón general, aparte de los varios y notorios casos de religiosos partidarios de la teología de la liberación asesinados por escuadrones militares o paramilitares de ultraderecha, no estoy en condiciones de valorar el papel que las anteriores limitaciones religiosas han podido tener en el pasado en la evitación del contubernio religioso-militar y, por tanto, en la preservación de la democracia en México. Sin embargo, me pregunto si los graves riesgos indicados por ese argumento (de carácter consecuencialista, anoto ahora por lo que se dirá más adelante sobre ello) están allí todavía tan vivos hasta el punto de poder justificar tan severas restricciones a derechos ejercidos sobre todo en el ámbito de la sociedad civil. Sea como sea, es cierto que, como alega Rodolfo, la supresión del sufragio pasivo para los sacerdotes se podría justificar como una extensión de mi argumento sobre la exclusión de las razones idiosincrásicas de los espacios institucionales. Sin embargo, no termino de compartir esa extensión, pues aparte de la relevancia de nuevo aquí de la distinción antes propuesta entre la deliberación como proceso y como resultado, me parece que la aplicación de mi criterio debería ser, como propuso Rawls y yo concluí en mi anterior escrito, más un deber de civilidad que un deber sancionado jurídicamente. Sin contar con que la limitación de tal derecho político individual se asemeja más a la regulación de los tipos de autor que a una de carácter liberal, basada en las acciones.

Solo me resta por comentar el punto con el que Rodolfo Vázquez inicia su contribución a este debate: la cuestión de la relación entre laicidad y agnosticismo, 
una idea tan hondamente sentida por Rodolfo que resulta ser el hilo conductor de su último libro, todavía pendiente de publicación y que tuvo la gentileza de enviarme: No echar de menos a Dios: itinerario de un agnóstico, un libro que requiere mucha más atención de la que aquí puedo prestarle. La observación de Rodolfo proviene de mi uso del término "agnosticismo» con el significado de posición de duda, indecisión o indiferencia ante las creencias religiosas y mi subsiguiente calificación del ideal del Estado laico como meta-agnóstico, en el sentido de indeciso o indiferente en cualquier posición a propósito de la religión, incluido el agnosticismo individual. Rodolfo reacciona contra ambas calificaciones para defender que el agnosticismo es algo muy distinto y que «nada es más compatible con el Estado laico que la actitud agnóstica» (p. 416), excluyendo mi definición de tal término y, con ello, la necesidad de defender el meta-agnosticismo estatal.

Más allá de la mera discusión sobre palabras y de que, como reconoce Vázquez, el tema es un paréntesis al margen del «punto central en la argumentación» (pp. 415-416), creo que se puede aclarar brevemente el alcance de nuestro disenso, que me parece solo aparente en lo que a mi tesis concierne. Mi uso del término "agnosticismo», que tiende a corresponder a su origen y uso habitual ${ }^{4}$, tenía la función de reflejar la posibilidad de una tercera posición entre la creencia en alguna religión y la negación de la existencia de deidades y de un mundo trascendente o ultraterreno, habitual y genéricamente calificada como ateísmo. Recogía así una distinción tripartita muy convencional y trillada con la función de destacar que la libertad religiosa no debe restringirse únicamente a quienes profesan una religión en el sentido anterior, sino también a las otras dos categorías, de modo que tal libertad garantiza la licitud de profesar cualquier creencia «en materia» religiosa, sea a favor, en contra o indiferente a las religiones. Cuando utilicé la distinción era consciente de que el concepto de religión, o de creencia religiosa, es todo menos simple y que hay creencias, como el budismo, el panteísmo e incluso el deísmo, que según se cualifique aquel concepto pueden ser clasificadas como teístas o como ateas. Pero no necesitaba una distinción muy precisa entre las tres categorías ni entrar en ese debate para cubrir aceptablemente mis propósitos.

El amigo Rodolfo Vázquez tiene unos propósitos completamente diferentes, ajenos al debate sobre la naturaleza y alcance de la libertad religiosa. Su preocupación se dirige a la cuestión religiosa misma, sobre la que quiere defender la tesis, en la línea de la dworkiniana "religión sin dios», del agnosticismo como «comprensión de la religión como amor y comunidad» y como actitud de apertura a lo inefable que es compatible con la aceptación de la finitud de lo mundano. Así, la actitud de alguien es religiosa si aspira a una conexión con la totalidad del universo, bastando el compromiso con alguna idea de bien, de modo que el agnosticismo termina por oponerse claramente solo al nihilismo escéptico. En esta configuración conceptual, donde a veces son difusas las fronteras entre religión y no religión o entre el agnóstico y el ateo, el agnosticismo puede abarcar tanto el no pronunciamiento sobre la alternativa teísmo-ateísmo como la superación de un inmaduro ateísmo, o tanto la sustracción a la trascendencia como la suspensión del juicio sobre la divinidad, pero sobre todo se presenta como la «condición de posibilidad» de la

\footnotetext{
${ }^{4}$ La versión inglesa de la Wikipedia afirma documentadamente que el término agnosticism no tiene orígenes clásicos, y en particular como algo opuesto a la gnosis o gnosticismo del primer cristianismo, sino que fue acuñado por el biólogo inglés Thomas $\mathrm{H}$. Huxley en una conferencia en 1869 para afirmar su propia posición epistemológica de que lo divino y lo sobrenatural es científicamente incognoscible. El significado usual, sin embargo, es probablemente algo más amplio, hasta negar cualquier tipo de conocimiento, como lo refleja el diccionario de la RAE, que ofrece esta única acepción: «Actitud filosófica que declara inaccesible al entendimiento humano todo conocimiento de lo divino y de lo que trasciende la experiencia».
} 
coexistencia pacífica de cualquier posición ante la religión ${ }^{5}$. En esta última y precisa manifestación el agnosticismo creo que coincide plenamente con mi «metaagnosticismo» y eso confirma nuestro sustancial acuerdo respecto al tema de la laicidad. Respecto de la restante y mucho más compleja conceptualización de Rodolfo Vázquez, no estoy seguro de compartirla en todos sus puntos, pero sí tengo claro que, religioso o no, Rodolfo se encuentra entre las mejores personas que conozco en el mundo académico.

2. Cuestiones jurídicas... y éticas: relativismo, cientificidad y objetividad (Rodolfo Arango)

Sobre el comentario de Rodolfo Arango, comienzo abruptamente: ha dado en el clavo, ha encontrado en mis escritos lo que parece una relevante contradicción, que probablemente no se ve a simple vista y que yo no había advertido como suficientemente apreciable para mencionarla en mi prefacio al libro. Es el momento de reproducir aquí la pauta del gran helenista Gregory Vlastos que recojo en ese prefacio y que extiendo a los demás participantes en el seminario: «He cometido errores en el pasado y sin duda cometeré más en el futuro. Cualquiera que me los haga notar es mi amigo» (2020, p. 27). Pero antes de entrar en materia, quiero recordar algo en lo que todos los años insisto a mis estudiantes en los seminarios dedicados a analizar y debatir textos de los clásicos del pensamiento político. La fuente más segura para la crítica (y de paso el conocimiento) de un autor no es la crítica externa, en la que se contraponen ideas de otros autores o del propio crítico, sino la interna, la que procede de las contradicciones del propio autor. Si un autor se contradice, al menos sabemos que una de las dos afirmaciones es falsa o incorrecta, y si la contradicción es parcial (no del tipo "llueve y no llueve", sino "llueve y nieva") puede ocurrir que sean falsas o incorrectas las dos. Naturalmente, mucha de la gracia del análisis de esos textos clásicos está en ver si las contradicciones son reales o aparentes, si se debe distinguir entre el Platón joven, el maduro y el viejo, si hay un Hobbes contractualista y otro que prescinde de todo consentimiento o si, en fin, la esquizofrenia de un autor es insanable, como quizá le ocurra a Herder.

Ahora estoy preparado para intentar contestar, brevemente, al agudo comentario del amigo Arango, que ha visto bien que hay un primer Ruiz Miguel y un segundo Ruiz Miguel. Y ha visto bien, además, que la contradicción entre ambos es doble, porque afecta a dos temas distintos: por un lado, a la concepción metaética, inicialmente más bien relativista y después objetivista; $y$, por otro lado, a la concepción sobre el Derecho, inicialmente de claro implante normativista y recientemente más bien interpretativista o postpositivista. Los dos giros son ciertos, aunque como el diablo está en los detalles tendrá interés que yo trate de dar cuenta de uno y otro y de hacer algunas anotaciones que permitan precisar y completar el cuadro dibujado por Arango.

Mi posición metaética, como he dicho, fue originariamente la del historicismo relativista. Mis iniciales lecturas juveniles de Marx y Engels, en las que la ideología aparecía como una excrecencia de las relaciones de la clase propias de cada momento histórico, se vieron confirmadas después por la lectura más académica de Kelsen, Ross, Weber o los emotivistas ingleses, para quienes la moral y la justicia eran criterios en último término irracionales, así como por mi intenso estudio de Bobbio, que añadía la influencia del historicismo italiano y defendía que los valores últimos son producto de nuestra elección y no de la razón. No he ido a mirar mi bibliografía con detalle y no sé cuándo ni por qué pero en algún momento,

\footnotetext{
${ }^{5}$ En los anteriores apuntes incluyo también referencias extraídas del nuevo libro de Rodolfo Vázquez, No echar de menos a Dios: itinerario de un agnóstico (manuscrito).
} 
probablemente por la influencia de Ernesto Garzón Valdés, encontré autocontradictorio el relativismo metaético, que quería estar en misa y repicando al sostener dogmáticamente que todo en moral es relativo y, a la vez, al afirmar como correctos ciertos valores con una convicción que desmentía aquel presupuesto. Solo sé que en 1992, con motivo de un amplio seminario sobre «La figura y el pensamiento de Norberto Bobbio» celebrado en el Palacio de la Magdalena, al formular las diez paradojas en las que me pareció que podía resumirse su pensamiento, la única propiamente crítica, y la única que Bobbio rechazó como paradoja, fue la del «relativista creyente» (no en sentido religioso, claro, sino en el que estoy tratando aquí) (Ruiz Miguel, 1994, pp. 8-9; Ruiz Miguel, 2000, pp. 187-189; Bobbio, 1994a, p. 317; y Bobbio, 1996, p. 153). Por lo menos a partir de entonces, he profundizado en la crítica al relativismo en algunos otros escritos, en especial en el librito Relativismo y democracia (del que son una síntesis actualizada los tres apartados finales del capítulo 15 del libro), donde es explícita la influencia de la obra de Ronald Dworkin.

Pero donde la influencia de Dworkin es decisiva es en mi revisión de la teoría jurídica de matriz normativista, que no puedo negar y que es mucho más reciente que la revisión anterior, también porque mi dedicación a la teoría del Derecho nunca ha sido prioritaria, sobre todo en mis escritos. Por lo demás, no me parece que haya sido tanto un giro sobre mi modo de ver el Derecho en su conjunto, que sigo considerando al modo positivista tradicional como un conjunto de normas (reglas y principios) que constituyen el trasfondo de la interpretación, esta sí, ya considerada como una práctica social en la que aparece una cierta conexión (no identificación) con la moral a través de la pretensión práctica de encontrar la respuesta correcta, que es y debe ser característica de la dogmática jurídica y de la interpretación judicial. En el diseño anterior, además, yo he insistido en defender lo que he llamado «positivismo interpretativo», es decir, una cultura de especial respeto a la legalidad y a la seguridad que el Derecho debe garantizar. No estoy seguro de que mi propuesta ofrezca un diseño del todo coherente, pero de momento estoy dispuesto a defenderla.

Bajo el marco anterior de mis dos grandes giros, paso ahora a comentar o contestar alguna de las observaciones y preguntas del escrito del amigo Rodolfo Arango. Mi precisión fundamental es doble. Por una parte, a diferencia de lo que sugiere Arango, yo sigo sin creer que el Derecho tenga carácter científico, ni siquiera en el sentido débil y meramente analógico que él parece señalar de que el Derecho en general sea esencialmente correcto o justo. Me conformo con que el sistema jurídico en el que uno vive aspire a ser razonablemente justo, tanto sustantiva como procedimentalmente, y que sus instituciones, incluidas las interpretativas, tiendan y contribuyan a ese objetivo. Por otra parte, tampoco veo que ninguno de mis dos giros, según dice Arango, «debería suponer el abandono de la dicotomía estricta entre hechos y valores» (p. 427). En esto sigo siendo, un "dualista encarnizado», como de sí mismo dijo Bobbio (Varios, 1964, p. 281), pero además sigo acompañando en esto a la propia concepción metaética de Dworkin, cuya Justicia para erizos lo repite por activa y por pasiva. Por esta razón, alguna de las contradicciones indicadas por Arango puedo salvarlas mediante el expediente de la distinción sin acudir al cambio de opinión en el tiempo.

En efecto, creo que puedo seguir suscribiendo el sentido general de mi visión de la dogmática jurídica como técnica y no como ciencia, revisando solo mi crítica de aquel artículo a la hermenéutica y a la irremediable subjetividad de la interpretación. La jurisprudencia, y la interpretación jurídica, no son científicas, ni siquiera bajo el modelo de las ciencias sociales, porque su pretensión no es cognoscitiva, en el sentido de descriptiva-explicativa-predictiva, sino, precisamente, técnica, de actuación en la realidad social. Pero que la interpretación jurídica no sea científica no excluye en absoluto su pretensión de corrección y por tanto la aceptación de la 
posibilidad de objetividad. Eso sí, con la condición de que tal objetividad no se confunda con la científica, entendida como, al menos en una medida última y básica, correspondencia con la realidad fáctica. La objetividad jurídica, como la filosófica, se mueve en la esfera del deber ser y no puede pretender corresponder con realidad fáctica alguna: detrás de ella no puede haber más que coherencia y argumentos pertinentes. Y ello, superado el escepticismo, porque, efectivamente, siguiendo a Luciano Canfora, la verdad tiene que estar en alguna parte, aunque la jurídica no sea el mismo tipo de verdad que busca el historiador.

Termino tratando de responder brevemente a la pregunta que Rodolfo Arango me formula en el párrafo final de su contribución de si me sitúo más cerca de la teoría de la integridad de Dworkin, de carácter más sustantivo, o de la de Alexy, de carácter más procedimental. No me había planteado la disyuntiva, pero creo que mi propuesta de un positivismo interpretativo está probablemente más cerca del enfoque de Alexy y de su especial preocupación por el rigor interpretativo en defensa de la seguridad jurídica. Agradezco de veras a Rodolfo que me haya incitado a esta contribución a la crítica de mí mismo, por recordar aquí a Benedetto Croce, quizá el principal inspirador del historicismo bobbiano contra el que yo terminé reaccionando.

\section{La cuestión de la democracia: del ámbito a la marginalidad (Mauro Barberis)}

Mauro Barberis ha tenido la gentileza de escribir un texto clarificador en el que, además de mostrarse de acuerdo conmigo prácticamente en todo, añade unos valiosos comentarios que bien ilustran o bien complementan magníficamente las ideas por mí esbozadas en el capítulo 13 del libro, dedicado al ámbito de la democracia. En esta ocasión podré ser más breve, porque no tengo gran cosa que añadir a la síntesis que Mauro hace de mi escrito y al complemento histórico de las transformaciones del Estado jurisdiccional medieval, al legislativo y de este al constitucional. Únicamente haría una pequeña apostilla a su observación de que mi justificación última del método democrático en la autonomía individual corre el riesgo del regreso al infinito porque es una meta-meta-decisión que justifica la meta-decisión constitucional que resuelve el problema de la imposibilidad lógica de decidir sobre el ámbito personal de la democracia (ya que, por definición, no puede haber demos previo para decidir cuál es el demos). Creo que el regreso al infinito se puede evitar si se piensa que el criterio de autonomía se debe sustentar en cada individuo, en cada sujeto (como Mauro y todos los participantes aquí creo que lo aceptamos) y, en el límite, en la idea de un consentimiento hipotético que lo acepta unánimemente.

El amigo Barberis afirma que estamos ante «el texto más intrigante de la recopilación» (p. 433), entiendo que porque en él yo planteaba varios problemas de límites de la democracia y a Mauro le sugiere uno distinto y mayor que allí faltaba: la creciente marginalidad del voto democrático tanto en el Estado constitucional como en el ámbito internacional. Tengo poco que añadir al diagnóstico de que los dos ataques fundamentales al Estado de bienestar de la segunda posguerra que marcan su crisis desde hace algunas décadas son el neoliberalismo con su expansión de la globalización económica y el populismo con su extensión de las democracias iliberales (vuelvo sobre esto en el apartado siguiente). A ello se suma el viejo reto que para la democracia supone el predominio de los técnicos y de las instituciones contramayoritarias, sobre lo que no es este momento de profundizar ${ }^{6}$. También coincido con Barberis en la conclusión liberal de que la esfera política no es más que una entre otras varias, como el Derecho, la moral, la economía, la ciencia, la religión.

\footnotetext{
6 Sobre una institución contramayoritaria decisiva como los tribunales constitucionales me he pronunciado, moderadamente a favor, en Ruiz Miguel (2003, pp. 73-108; versión cast., pp. 51-84).
} 
Un tema de ardua complejidad en el que tiendo a disentir de Mauro Barberis (y Jordi Ferrer) es el de la posibilidad de solucionar «el problema de los independentismos europeos» con la transformación de la Unión Europea en una federación de regiones que sustituyeran a los Estados (p. 436). Se trataría, en definitiva, de multiplicar, presumiblemente sobremanera, el número de entidades políticas, con el ahorro de la supresión de ese nivel intermedio que hoy configuran los distintos Estados. En un mundo que careciera de las pasiones nacionales tal vez ese modelo pudiera funcionar, aunque la multiplicación de actores de una institución no parece en principio destinada a aumentar la eficiencia. Con todo, al igual que las propuestas de constituir entidades políticas de dimensión más reducida que las actuales, avanzadas en la época de la Independencia americana por los antifederalistas y recuperada recientemente por Brian Barry (Ruiz Miguel, 2020, p. 467), la Europa de las regiones me parece más un diseño fatto a tavolino que practicable. Como dijo Catalina la Grande de los proyectos de Diderot, mientras el papel se presta a todo, la política debe contar con la naturaleza humana, "que es irritable y se ofende con mucha facilidad» (cit. por Blom, 2012, p. 346).

Para concluir, me queda una duda que quiero dejar dicha para poder continuar el debate: que la política, y la democracia, hayan ido perdiendo importancia de hecho no obliga necesariamente a concluir con una idea fuerte sobre su marginalidad. No afirmo en absoluto que eso es que lo que termine por sostener Mauro Barberis, pero sí me parece importante terminar subrayando por mi parte que el hecho de que la política democrática sea hoy menos, y quizá incluso poco importante, no significa que no debería ser de lo más importante y decisivo. Y mantener su valor me parece también importante y decisivo frente a los grandes retos que afronta la superpoblada humanidad en el próximo futuro.

\section{Cuestiones de igualdad: de las igualdades a La Igualdad (Roberto Gargarella)}

La contribución de Roberto Gargarella, puño de hierro con guante de terciopelo, presenta un severo contenido crítico bajo una forma bien temperada que agradezco de veras por su honestidad y su afabilidad. Hace mucho tiempo que sé que no todo lo que uno escribe, y ni siquiera algo de ello, puede recibir el aprecio de todo el mundo. $Y$ el que solo uno de los cuatro escritos considerados por Roberto haya suscitado su casi completo acuerdo, mientras que el conjunto de los tres restantes le hayan causado una "cierta incomodidad» que en ocasiones puede haber llegado a fatigarle, es un porcentaje bajo que lamento pero que no toca a la relación amistosa que mantenemos. En todo caso, puedo entender bien y explicar las razones de nuestros desacuerdos, tal vez producto en buena medida a diferencias ideológicas y de talante personal -esto es, antes a circunstancias ajenas a mi control que a mis elecciones-, sin necesidad de compartir todos las observaciones críticas señaladas en su comentario, algunas de los cuales asumiré, mientras otras tal vez admitan justificación o al menos excusa. Vayamos por partes, como recomienda la mejor filosofía analítica.

Comienzo por aceptar solo en parte la halagüeña comparación de mis escritos con los de Ronald Dworkin, que me parece exagerada por poner al lado a un enano y a un gigante y también dudosa por asemejar a un estudioso más bien del tipo zorro con un autodeclarado e indiscutible erizo (que, dicho sea de paso, frente al $A$ Matter of Principle, explica el plural duplicado en el título de mi libro). Puedo aceptar en cambio las dos semejanzas sobre las que giran los reparos centrales de Gargarella: que el promisorio aparato de distinciones analíticas de mis escritos tiende a producir conclusiones muy modestas y, por añadidura, conservadoras, dos calificaciones que pueden tomarse como independientes entre sí y que, dicho de momento solo como mera excusa, parecen más graves en un erizo, que pretende tener un conocimiento del mundo completo, cerrado y acabado, que en un zorro como yo, que únicamente 
aspira a no perderse en un mundo que tiende a ver como inabarcable y laberíntico. Volver a la socorrida dicotomía de Isaiah Berlin me resulta casi inevitable para agilizar una explicación del primer y más general desencuentro de Gargarella con mis escritos sobre igualdad, que yo relaciono con su querencia intelectual hacia el tipo erizo.

Solo un erizo, me parece, afirmaría que el capítulo 16 del libro, dedicado al concepto de igualdad (2002), despliega un «pantano de distinciones [...] fatigosamente exploradas»-donde yo leo más bien «fatigosamente atendidas», dicho sin destemplanza- que no terminan por resultar imprescindibles para entender lo que se dice en otros capítulos porque son «no esenciales para el tratamiento específico de la cuestión de la igualdad [...y para] el estudio que se propone Ruiz Miguel en el libro» (pp. 441-442). En lo descriptivo, Gargarella tiene toda la razón, pues nunca he buscado tal tipo de conexión ni, como muestra el propio capítulo 16, tal conexión existe. En lo valorativo, en cambio, me parece injusto el reproche de que la aportación de ese capítulo, con sus distinciones, está desconectada de mis demás reflexiones sobre la igualdad, a diferencia del caso de Dworkin, pero no precisamente porque yo sea un «destacadísimo profesor» con amplia formación analítica y de gran dedicación a las distinciones conceptuales (p. 442). Sencillamente, mi preocupación cuando escribí ese capítulo era el problema de si la idea meramente formal de igualdad (su concepto) era o no realmente algo valorativamente vacío, a la que Peter Westen había dedicado dos extensos escritos en 1981 y 1990 (Westen, 1981, pp. 537-596; y Westen, 1990), a diferencia de las concepciones sustantivas de la igualdad, que nadie ha puesto en duda que comprometan complejas y profundas valoraciones. En esa exploración lo primero que me llamó la atención fue la propia distinción entre el concepto y las concepciones, que inicialmente atribuí a Dworkin (que es quien sigue llevando la fama, como muestra Gargarella, seguramente porque el mismo Dworkin no dio a entender otra cosa) pero que terminé rastreando en Rawls y, a través del reconocimiento de este, en Hart ${ }^{7}$. Como esa distinción resultó ser más mucho más ambigua de lo que se podía sospechar le dediqué una buena parte del escrito, centrándome en otra parte en desmenuzar la idea formal de igualdad para tratar de ver si era tan vacía. Mi conclusión, más bien breve, fue que tenía un contenido mínimo, circunscrito al criterio de racionalidad imparcial típico del lenguaje moral, luego siempre rellenable bajo un criterio de razonabilidad según las distintas concepciones de lo arbitrario. Puede que la conclusión fuera no solo breve sino también pobre, aunque se podría decir en mi descargo que aunque hubiera sido más pobre todavía, por confirmar en vez de revisar mínimamente el carácter formal del concepto de igualdad, el proceso de justificación de la conclusión habría sido en mi opinión un ejercicio intelectual valioso, de modo similar (salvadas las distancias) al valor del intento de demostración de una conjetura matemática.

En realidad, el hilo conductor del capítulo sobre el concepto (formal) de igualdad es la discusión de si la distinción entre concepto y concepciones es categorial, de modo que el análisis y alcance del primero es o no independiente de las segundas. Más aún: esa discusión ni siquiera consideraba que no solo hay diferentes concepciones de la igualdad sino también distintas clases de igualdad, que no solo pueden seguir a su vez diferentes concepciones sino que, sobre todo, operan de distinto modo según el objeto al que se refieren, como la igualdad política, la

\footnotetext{
7 Tras la publicación del libro, Manuel Atienza me hizo notar en un correo electrónico que, a su vez, Hart probablemente se inspiró en su distinción en el libro de Chaïm Perelman De la justice (1945), donde distingue la noción de justicia como regla formal y las concepciones de la justicia como reglas materiales (vid. Perelman [1964, pp. 15-42]). En mi respuesta, contesté que, más allá de la expresa llamada de atención a la distinción concepto-concepciones, que pertenecería a Hart, seguramente tenía razón en su observación pero que el fondo del asunto se podría rastrear al menos hasta la visión aristotélica de la justicia distributiva, que es siempre (formalmente) igualdad en los merecimientos, aunque (materialmente) cada uno vea los merecimientos de distinta manera.
} 
igualdad distributiva, la igualdad ante la ley, la igualdad de oportunidades, la igualdad de estatus, la igualdad de recursos o de bienestar, etc. En contraste, el escrito de Gargarella está atravesado por expresiones referidas a mi «análisis de la "igualdad"», mi «estudio de la igualdad», «la reflexión filosófica sobre la igualdad», etc. (pp. 439, 442 y 444; cursivas mías), como si solo existiera algo así como La lgualdad -me recuerda a "La Idea" común a los revolucionarios del siglo XIX-, una idea que vendría negada por «las profundas injusticas y desigualdades que nos rodean» y sobre la que yo habría concluido que es «casi» una forma vacía, lo que terminaría por «colapsar la filosofía política en el análisis conceptual».

Así, en aquella conclusión mía del último apartado del capítulo 16, donde cito una referencia de Rawls a las ideas de "arbitrariedad» o "adecuación», Gargarella me reprocha el no haber desarrollado la concepción rawlsiana sobre la arbitrariedad de las circunstancias de las que las personas no son responsables, como la raza, el sexo, el talento individual, etc., es decir, sobre el criterio central de lo que por comodidad expositiva denominaré en adelante el igualitarismo de la suerte (que en realidad, como Gargarella lo mostró en otro lugar [Gargarella, 1999, cap. 3], Rawls solo aceptó limitadamente). Es más, al eludir tratar ese criterio yo habría terminado por presentar «la teoría de que cambió la historia del pensamiento igualitario» (p. 444), la teoría rawlsiana, como una propuesta meramente formal, imprecisa y abierta a cualquier contenido.

No puedo aceptar esta crítica, que creo fuera de contexto. En el final del capítulo que estoy comentando, cité un texto de Rawls en el que aludía a las ideas de «arbitrariedad» y "adecuación» al efecto de calibrar su posible papel como nexo de unión entre el concepto y las concepciones de la igualdad, pero precisamente en el mismo contexto y sentido en que se expresaba el propio Rawls, es decir, afirmando lo mismo que Gargarella me reprocha ahora a mí: que aquellas ideas son compartidas por distintas concepciones de la justicia. En aquella discusión habría estado fuera de lugar que yo intentara cerrar la posible brecha entre el concepto y las diversas concepciones desarrollando la propia concepción de Rawls sobre la arbitrariedad de tratar desigualmente a las personas por rasgos de los que no son responsables, por extraordinaria que sea su potencia crítica (sobre lo que volveré un poco más adelante). Sencillamente, conforme al alcance y el objetivo de mi escrito «Concepto y concepciones de la igualdad», allí me mantuve en el mismo plano formal que Rawls, exactamente con su misma argumentación y sacando la misma conclusión:

Those who hold different conceptions of justice can, then, still agree that institutions are just when no arbitrary distinctions are made between persons in the assigning of basic rights and duties and when the rules determine a proper balance between competing claims to the advantages of social life. Men can agree to this description of just institutions since the notions of an arbitrary distinction and of a proper balance, which are included in the concept of justice, are left open for each to interpret according to the principles of justice that he accepts. [...] Clearly this distinction between the concept and the various conceptions of justice settles no important questions. It simply helps to identify the role of the principles of social justice (Rawls, 1999, p. 5; cursiva mía).

Paso al comentario del capítulo 18, sobre la igualdad política (también del 2002), sobre el que Roberto Gargarella dirige una crítica al escaso rendimiento de mi método analítico por el carácter pobre $\mathrm{y}$, por añadidura, conservador de mis conclusiones, en especial por no tener en cuenta la relevancia central de la distinción entre circunstancias y elecciones, es decir, el criterio básico del igualitarismo de la suerte (cf. pp. 440ss). 
En primer lugar, Gargarella destaca que mi profusa utilización de las distinciones crearía una laberíntica madeja de la que no sale gran cosa de especial sustancia, lo que me ha recordado la antigua fábula del parto de los montes. Como ya he sugerido, no acepto el reproche de que mis distinciones sobre el concepto de igualdad no sean utilizadas para el específico tema de la igualdad política, pero no porque en último término puedan ser inútiles en general, como se podría deducir del reproche, sino simplemente porque se referían a otro problema y no tenían ni podían tener tal pretensión. En cuanto a las nuevas distinciones del escrito sobre la igualdad política, en gran parte procedentes del propio Dworkin, reconozco la relativa complejidad del método allí utilizado de entrecruzar tres concepciones o modelos de tal igualdad (que allí denomino procedimental, de preferencias y finalista) con varias diferencias en su aplicación (igualdad horizontal y vertical, de impacto y de influencia, ex ante y ex post, etc.). Es verdad que, como dice Gargarella, en este escrito no me ocupo «de las profundas injusticias y desigualdades que nos rodean» ni de la relación entre la idea de igualdad democrática con los impuestos progresivos o con el terrorismo o con el control judicial (pp. 442-443): en mis numerosos escritos, quizá demasiados, me he ocupado de muchas cosas pero no de todas, aunque al último punto -un paso cada vez- le dediqué un artículo no incluido en el libro ${ }^{8}$. De otras objeciones -que no tengo en cuenta el igualitarismo de la suerte y que no abordo más críticamente la democracia representativa hasta tratar temas «hoy» de sentido común en la literatura, como la erosión, el retroceso, la muerte lenta o la fatiga democráticacabe deducir que Gargarella hubiera escrito un artículo bien diferente y quizá yo mismo las asumiría si tuviera que volver a escribir el artículo hoy, casi veinte años después (en realidad, algunas de esas cuestiones las he abordado en parte en algunos artículos no recogidos en el libro) (Ruiz Miguel, 2016, pp. 621-642; Ruiz Miguel, 2005, pp. 2.129-2.152; y Ruiz Miguel, 2005a, pp. 125-137, que recoge parcialmente, con correcciones y adiciones, el anterior).

Lo que no puedo asumir, sin embargo, es que mi aportación en este capítulo se pueda reducir a la idea de que avanzo «severas críticas al igualitarismo de Dworkin» para terminar "por describir a la igualdad [sic] como un ideal que "no resulta... tan estricto e importante como podría parecer a simple vista"» (p. 443; el texto entre comillas internas está en Ruiz Miguel [2020, p. 489]; el término en cursiva es mío). Ya he dejado claro que Gargarella tiene solo ojos para La Igualdad, entendida bajo el prisma del igualitarismo de la suerte como justicia correctora de las circunstancias en favor de las decisiones, pero aunque seguramente no interesen a todo el mundo, hay muchas más cosas en mi escrito. En todo caso, mi afirmación anterior confirmaría la convicción de Gargarella de que mis conclusiones son conservadoras. Advierto ya de que no me interesan los debates de etiquetas sino la corrección o no de las razones que están detrás de las posiciones que cada uno mantiene. Ciertamente, yo mismo avanzaba que la conclusión entrecomillada por Roberto «tal vez parezca demasiado conformista» (2020, p. 489), pero como ya sugiere mi actual cursiva su función no era en realidad conservadora sino crítica. $Y$, en efecto, en mi escrito reconozco claramente que los sistemas que consideramos democráticos son especialmente poco exigentes en materia de igualdad política, especialmente en la salvaguardia de una justa igualdad de oportunidades en libertad de expresión y del principio «una persona, un voto» (cf. 2020, pp. 473 y 481-487). Y ese reconocimiento asumía la doble función crítica de, por un lado, distanciarme de una concepción como la de Dworkin, cuyo idealismo yo presumí que corría el riesgo de justificar en exceso el sistema estadounidense, y, por el otro, de toma de

\footnotetext{
${ }^{8}$ Me refiero a Ruiz Miguel (2003, pp. 73-108). Por lo demás, aprovecho aquí para decir que en mi artículo original sí cité el libro de Dworkin Sovereing Virtue, en efecto anterior a él, aunque ciertamente me centré estrictamente en el tema de la igualdad política y el artículo de Dworkin dedicado a ella.
} 
conciencia previa, como viene a decir la última frase de mi escrito, para poder empezar a pensar en ir reduciendo dichas desigualdades.

En el comentario del capítulo 17, escrito en 1994 y dedicado a la relación entre liberalismo y socialdemocracia, vuelve el reproche a mi conservadurismo, manifestado ahora en una interpretación de la concepción igualitaria de Rawls que, según Gargarella, la «acerca estrechamente» al neoliberalismo de Hayek. Creo que si el capítulo se lee con cuidado y caridad interpretativa el acercamiento no es tan estrecho, porque en él se señalan, es cierto, las relativas aproximaciones entre el subsidio de subsistencia mínimo de Hayek y el principio de diferencia de Rawls, pero también se destaca «una diferencia crucial por encima de tales aproximaciones», la existente entre poner el umbral en la pobreza absoluta o en la pobreza relativa, a lo que se dedican varias páginas (cf. 2020, pp. 445-449). Debo reconocer, sin embargo, que Gargarella tiene razón en subrayar que mi interpretación de Rawls contrasta con la suya, compartida con lo que podríamos llamar la Izquierda rawlsiana. Yo me sitúo en una interpretación más moderada, que comienza por no entronizar el principio de diferencia como único criterio de justicia (también están el sistema de iguales libertades básicas y el principio de justa igualdad de oportunidades), e incluso concedo, como hacía en mi escrito, que, aun sin forzar el pensamiento de Rawls, he podido derivar conclusiones no explícitas en él. También reconozco que el capítulo que comentamos, como algunos otros de mis escritos, tiene agujeros bibliográficos y de argumentación: ni lo he leído todo sobre todo lo que he escrito ni, seguro, he profundizado siempre lo suficiente, especialmente en los temas en que existe una literatura ingente y compleja.

Donde el amigo Gargarella sí aplica el principio de caridad interpretativa, y muy generosamente, es en el último apartado de su comentario, donde relaciona mi posición en estos escritos con el «momento feliz» de la socialdemocracia española (pp. 445 y 447ss). Hay, en efecto, una relativa coincidencia de fechas con el período en el que se construyó el estado de bienestar después de la transición, en la que, si bien unos años antes se había fraguado una aceptación mutua del pluralismo político, ya desde los años 90, más infelizmente, comenzaban en España los períodos de crispación política que desmienten el consenso inicial, así como también despuntaban «los oscuros nubarrones de los nacionalismos agresivos y excluyentes y, sobre todo, del racismo antiinmigratorio», según lo denuncian las últimas páginas del capítulo 17, escrito en 1994 (2020, pp. 453-454). Ese capítulo, en realidad una ponencia presentada a un congreso en recuerdo de Renato Treves, estaba traspasado por la convicción de la bondad de converger en una defensa básica de los pilares del Estado social -la educación, la sanidad y la seguridad social-y, en consonancia con ello, aun sin negar las diferencias entre izquierda y derecha, por la invitación a asentar «una arena común para la discusión» (2020, p. 452). Ahora apreciamos lo mucho de coyuntural que tenían aquellas condiciones político-económicas, por mí parte allí avanzadas con cautela, pero cuando elegí el escrito para el libro me pareció que, en tiempos de polarización y de retroceso en los derechos sociales como los actuales, recordar e incluso apelar a aquel espíritu podía y puede servir de referencia de un modelo aceptable ${ }^{9}$.

\footnotetext{
${ }^{9}$ La verdad es que tuve alguna duda en la elección de este capítulo, porque desarrollé el mismo tema en un artículo escrito unos pocos años después de manera menos expresamente comprometida y más detallada y amplia, en donde trato también el tema de la renta básica universal y dedico cierto espacio a la crítica de Gerald Cohen a Rawls (vid. Ruiz Miguel, 2002, pp. 211-242; donde, por cierto, en la última nota remito al libro de Gargarella Las teorías de la justicia después de Rawls «para una exposición mucho más rica del tema»). Sin embargo, la gran extensión de este artículo y la pereza de pedir la autorización a la editorial me inclinaron al que finalmente incluí, aunque tengo la impresión de que Roberto Gargarella no lo habría interpretado de manera muy diferente.
} 
Concluiré mis comentarios a las observaciones de Roberto Gargarella intentando responder, siquiera sea en esquema, a su pregunta final sobre qué mantendría, corregiría o precisaría yo hoy respecto de lo dicho en el libro en materia de igualdad. Como él mismo apunta, una conclusión como la del párrafo anterior, muy localizada tanto espacial como temporalmente, podría leerse de nuevo bajo el criterio «conservador» de que en Europa y España no estamos tan lejos del modelo perdido, que estaría llamado a volver tras el actual paréntesis recesivo no solo en el campo económico-social sino también en el político. No estoy nada seguro de que en un mundo tan desestructurado como el actual, y bajo la creciente presión global sobre el medio y los recursos naturales, vayan a ir por ahí las cosas, pero como propuesta normativa abierta y revisable para el siguiente paso (no como modelo ideal) estaría dispuesto a mantenerla y extenderla más allá del ámbito europeo. Si eso parece conservador no lo será porque yo crea que cualquier tiempo pasado fue mejor sino porque tiendo a ver cualquier otro futuro como peor.

Desde el punto de vista político, me parece esencial mantener los valores de la democracia liberal, que con todas sus deficiencias e insuficiencias solo parece tener como alternativa a sistemas políticos entre aterradores, temibles y deplorables, si se quieren poner en una escala los totalitarismos fascistas, los comunistas y los autoritarismos de variada laya, incluidos en último lugar las hoy llamadas democracias iliberales. Mi idea, quizá equivocada, es que la democracia liberal se debe transformar progresivamente y que las transformaciones revolucionarias o radicales a partir de constituciones democráticas tenderán a ser a peor, lo que seguramente también tiene un sabor conservador o, al menos, moderado, al menos para quien no haya tenido nunca o no haya perdido las libertades democráticas.

En cuanto a mi criterio de justicia distributiva, sigue yendo en la línea socialdemocrática en la que yo interpreto la concepción de Rawls, sin conceder al igualitarismo de la suerte un lugar tan central, ni en general ni en esa concepción, como el que pretende Gargarella ${ }^{10}$. No es este el momento de desarrollar semejante tema, por lo que espero que basten unas pocas líneas para situar mi posición: acepto, por supuesto, que en principio las recompensas socio-económicas deben ser más sensibles a las decisiones que a las circunstancias. Sin embargo, sin llegar a mantener el criterio de Kant de que todo individuo debe poder conseguir cualquier nivel económico o posición social «hasta el que puedan llevarle su talento, su aplicación y su suerte» (Kant, 1986, p. 30), el rígido criterio opuesto de que la justicia exige corregir todos los factores dependientes de la suerte (incluido el talento y demás dotes naturales) me parece simplista y desatinado.

En un mundo ideal, con todas las dificultades de contar con una organización internacional democrática apropiada (sobre lo que diré algo más en el apartado siguiente), desde luego que quedarían muy atenuadas las actuales enormes desigualdades producidas por la región y la familia de nacimiento. Por el momento, sin embargo, aun aceptando alguna relevancia de ese criterio en ciertos contextos, pretender enderezar o compensar todas las desigualdades debidas a la suerte, al menos entendido ese criterio de manera perentoria y urgente, como cuestión de justicia, se me representa como una pesadilla antiliberal, tanto en su proceso como en sus resultados. Además de considerar aceptables las diferencias por la suerte elegida o asumida ${ }^{11}$, algún severo trade-off habrá que admitir, además, para resolver

\footnotetext{
${ }^{10}$ No me resisto a citar y recomendar aquí la crítica a tal forma de igualitarismo en el soberbio libro de Queralt (2014).

${ }_{11}$ Puesto que puede haber lectores jóvenes de este intercambio, quizá no sea del todo inoportuno traer aquí, siquiera sea en nota, una ilustración de la suerte elegida que he aportado en alguna conferencia pero no, creo recordar, en ninguno de mis escritos. En su relato Las mil docenas, Jack London cuenta la historia de David Rasmunsen, que pensó hacerse rico llevando a vender mil docenas de huevos a
} 
el arduo problema de discernir lo que corresponde a la suerte y lo que corresponde a la decisión tanto en el comportamiento individual como en las interacciones sociales: ¿qué tipo impositivo consideramos justo exigir al jugador de fútbol que gana millones de euros gracias a la doble suerte de, por un lado, ser ágil en regatear y marcar gol con una pelota, suerte que él ha decidido desarrollar mediante su esfuerzo, y, por otro lado, de que ese juego apasione también a millones de personas que eligen pagar con gusto unos pocos euros por contemplarlo en directo o por televisión?

Observaciones como las anteriores pueden confirmar, de acuerdo con la percepción de Roberto, mi vieja adscripción a una socialdemocracia moderada, que, en el contexto en el que he vivido, me sitúa en una posición intermedia entre la reconciliación con el mundo y el afán de transformarlo radicalmente. En todo caso, para transformar el mundo, si no se quiere incurrir en errores y horrores pasados, me parece preciso antes conocerlo y entenderlo para poder luego ir transformándolo gradualmente. En los valiosos libros y escritos de Roberto Gargarella he aprendido mucho. He seguido aprendiendo en su contribución a este debate, que le agradezco mucho también como incitación a esta autocrítica mía, que a diferencia de la clásica no ha resultado tan negativa.

5. Cuestiones cosmopolitas: pacifismo, democracia internacional, nacionalismo (Ermanno Vitale)

Solo me resta comentar, me temo que de nuevo con alguna extensión, la no menos extensa contribución de Ermanno Vitale, amigo fraterno por nuestro afecto a Norberto Bobbio, común padre intelectual. A pesar de ello, o quizá por ello mismo, su aportación está marcada por una distancia que Vitale califica como «irremediable» y que, en efecto, salvado el primer párrafo de salutación y de anuncio de «alguna modesta nota al margen», comienza enseguida a subir el tono in crescendo hasta terminar en lo que no he podido evitar calificar como cercano a una strapazzata coi fiocchi, una expresión que Bobbio utilizó en la polémica Quale socialismo? (1976, p. 87) de los años 70 y que yo tengo grabada desde entonces por la dificultad de su traducción: hoy propondría un rapapolvo de campeonato. Pero cercano al Bobbio de aquella ocasión (que es también el de otras muchas ${ }^{12}$ ), apenas me reconozco en el conjunto de la pintura que Vitale hace de varias de mis ideas, y respecto de los detalles que las retratan mejor, aun críticamente, creo que puedo volver a defenderlas. Conviene precisar no obstante que más allá de su apariencia de integral, su crítica se dirige sobre todo a los escritos del último apartado del libro, sobre paz y guerra, democracia internacional y nacionalismo (traído este último tema a propósito del conflicto catalán).

Ermanno ilustra nuestra «irremediable distancia» en la manera de entender la filosofía política y la tarea de los intelectuales mediante dos citas: una, la admonición de Rousseau contra aspirar solo a lo factible, que no sería más que un compromiso con el mal que se viene haciendo sin logro de bien alguno; y la otra, una de las llamadas de Bobbio a cultivar una filosofía militante, definida como una toma de

Dawson, la helada ciudad del oro en Alaska, calculando que multiplicaría por cinco su inversión. A pesar de que a mitad de camino ya había gastado casi tanto dinero como había creído poder ganar, consiguió llegar a Dawson tras penosas peripecias y sufrimientos. Allí comenzó a vender los huevos a un precio que multiplicaba por dieciocho su cálculo inicial. Pero, para su desgracia, enseguida se enteró de que toda su mercancía se había podrido en algún momento del trayecto. El relato termina con el suicidio de Rasmunsen, ahorcado con la cuerda de su trineo (que este caso ilustre la posibilidad de justificar ciertas desigualdades producidas por el mercado no implica, sin embargo, que no haya otras razones de justicia para establecer correcciones al mercado y a sus desigualdades).

12 Sin ánimo de exhaustividad, es también el Bobbio de la polémica un cuarto de siglo antes, en la primera mitad de los años 50, recogida en los ensayos de Política e cultura (1955) o, casi un cuarto siglo después, el del Elogio della mitezza (1993; ahora en Elogio della mitezza e altri scritti morali, 2000). 
posición no partidista -esto es, ni obediente ni sectaria- que tras haber escuchado y tratado de comprender, asume la parte propia de responsabilidad hasta decir no solo lo que se piensa sino de qué lado se está (cf. pp. 451-452). En realidad, se trata de dos ideas bastante diferentes, la primera esencialmente de contenido y la segunda más bien de actitud y modo de hacer. Tan diferentes, además, que no tengo más remedio que dar la razón a Vitale sobre mi lejanía de ese Rousseau y, a la vez, negar su implícito reproche de que me haya apartado de la enseñanza de Bobbio. Más todavía, creo precisamente que ha sido la enseñanza y el ejemplo de Bobbio, que por lo demás debía ser congenial con mi modo de ser, lo que me ha ayudado a apartarme del gusto por las quimeras, rousseaunianas o de otra índole. En ello quizá me ha ayudado la filosofía del Derecho, o mi modo de entenderla, en la medida en que razonar sobre el Derecho obliga a poner los pies en la tierra de lo posible y permite ayudar a practicar una filosofía que no es ni de gabinete ni de barricada. Vayamos por partes, dejando para la última parte la cuestión de mi recepción de la lección de Bobbio, donde habrá ocasión de ir haciendo las sumas.

Por la parte de los contenidos, es decir, de lo que Ermanno Vitale considera falta de «impulso utópico» en mis reflexiones (p. 452), podría replicar con una cita opuesta de Rousseau, al que siempre es fácil encontrar en contradicción: aquella en la que, tras recibir del sobrino del Abée de Saint Pierre los manuscritos de este utopista ilustrado, el ginebrino muestra su decepción por no haber encontrado tesoros sino

visiones superficiales, proyectos útiles pero impracticables debido a la idea, de la que el autor nunca pudo salir, de que los hombres se conducen por sus luces más que por sus pasiones [sin dejar de caer] de error en error en todos los sistemas, por haber querido hacer a los hombres semejantes a él, en lugar de tomarlos tal como son y como continuarán siendo (Rousseau, 1959, p. 422).

Se diría que solo uno de estos dos Rousseau puede estar más próximo a la verdad. Vitale ha elegido el primero y yo estoy, como él dice, en las antípodas, pero para mostrar que es posible y hasta deseable un antiutopismo ilustrado, que veo muy emparentado con el illuminismo pesimista de Bobbio, me puedo servir de la vitriólica pluma de Voltaire:

Todos decían que los dioses habían dispuesto que hubiera reyes para dar fiestas todos los días mientras fuesen variadas, que la vida es demasiado corta para gastarla de otro modo, que los juicios, las intrigas, la guerra, las disputas de los sacerdotes que consumen la vida humana, son cosas absurdas y horribles, que el hombre ha nacido para disfrutar [...]. Tan excelente moral sólo ha sido desmentida por los hechos (Voltaire, 1986, pp. 101-102).

Voltaire prueba bien que la distancia, la desconfianza, incluso el disgusto respecto del «impulso utópico» no es incompatible con el espíritu crítico, con la toma de posición responsable y con la defensa de los criterios éticos que se creen adecuados. $\mathrm{Y}$, francamente, sin pretender igualarme a ninguno de los grandes autores, yo creo haber intentado cumplir mi parte en la crítica a lo irracional de lo existente y en la defensa de los principios que podrían ir mejorando la realidad.

No me reconozco en el retrato de mi posición como situada en una tierra intermedia entre la «utopía razonable» y el realismo cínico o trasimaquiano que me colocaría en la mera defensa de lo existente (p. 452). Aunque no lo dice categóricamente, Ermanno oscila entre dos bocetos de mi posición bien diferentes: que me sitúo en un terreno intermedio que consagra lo existente y que tiendo a eludir el afirmar de qué parte me pongo, lo que equivaldría a intentar no estar en ninguna lugar; solo en el ensayo sobre Cataluña ve Vitale una clara toma de posición, y es en 
favor del statu quo (lo que, dependiendo del status, preciso yo, podría no tener nada de malo) (p. 453). Pero me temo que, me ponga como me ponga, para él tiendo a situarme en una tierra de nadie en la que la que todo lo real es racional. Dejando el asunto de Cataluña para el final, creo que su retrato se basa en buena parte en una mala interpretación de mi posición sobre la democracia internacional y en un malentendido sobre el consecuencialismo como respuesta a la conflictividad internacional. $Y$ en la parte restante, en cambio, lo que seguramente ocurre es que, aun dentro de un espectro de proximidad, Vitale no comparte los criterios sustantivos que yo he mantenido sin oscuridades ni evasión alguna.

En su comentario al capítulo 22 -el único del libro que tiene a Bobbio como protagonista- el amigo Vitale no interpreta bien el sentido de mi apelación al socialismo liberal como modelo ideal y extrae una conclusión insuficiente y superficial sobre el punto de la posibilidad de internacionalización de la democracia. Ermanno comienza por reprocharme que califique al socialismo liberal como «uno de los principales oxímoron bobbianos» y que a la vez lo considere como la «difícil y abierta síntesis» del modelo político del mismo Bobbio, lo que constituiría una contradicción, un oxímoron de segundo nivel (p. 453). La verdad es que en mi descripción me limité a resumir, reconozco que muy expeditivamente, la propia posición que el común maestro desarrolló, de manera compleja y crítica, en su escrito más amplio y principal sobre el socialismo liberal, donde acepta sin problemas su calificación como oxímoron o ircocervo para concluir que su valor teórico como síntesis había sido hasta entonces débil, al tratarse de una construcción doctrinal artificial o sobre el papel (Bobbio, 1994, pp. 58-59) ${ }^{13}$. En todo caso, para una lectura mínimamente caritativa y que tenga en cuenta a Hegel, no veo nada de extraño ni paradójico en defender la posibilidad de síntesis o mediaciones que intentan superar oxímoron, especialmente cuando hablamos de doctrinas políticas. Lo importante es que, más allá de las denominaciones y de las inevitables variaciones doctrinales y prácticas, el modelo del socialismo liberal no propone algo esencialmente distinto del espectro del pensamiento socialdemócrata o de socialismo democrático, que es el modelo que he compartido con Bobbio o Elías Díaz desde mi juventud y que Francisco Laporta recuerda en su prólogo. Aunque ya lo había declarado en el apartado anterior, no me importa repetirlo ahora porque, en efecto, en el artículo que comento no aparece expresamente dicho, pero no por una supuesta «tendencia a no tomar partido», como dice Vitale (p. 453), sino seguramente porque lo di tan por supuesto que no encontré necesario decirlo.

En todo caso, la interpretación que hace el amigo Vitale del artículo dedicado a la democracia internacional no recoge bien el hilo de mi argumento básico, sin duda porque yo debería haberlo dejado más claro. Dicho muy sintéticamente, ese hilo era que el modelo democrático (liberal o socialdemocrático) bobbiano puede y debe considerarse un ideal regulativo en la esfera internacional, propugnando un Estado federal mundial que no es imposible de pensar ni de realizar, es decir, que es posible sea en términos conceptuales o sea en términos empíricos absolutos, por más que hoy resulte muy difícil ver su inmediata practicabilidad, especialmente, decía yo, para el limitado plazo previsible de «nuestra vida y la de nuestros hijos» (2020, p. 592). Tal es el contexto de mi referencia al dilema del prisionero dadas las actuales condiciones internacionales, ante la que todavía espero un argumento en contra, si no una refutación: hic Rodhus, hic salta. Pero esas condiciones podrían variar en un futuro indeterminado y, como anota Mauro Barberis en su comentario (pp. 434-435), aquella misma posibilidad de una organización democrática internacional ya aparece en mi

\footnotetext{
${ }^{13}$ En el párrafo final, Bobbio terminaba distanciándose incluso del uso de la categoría, afirmando que "parece caminarse un poco más con los pies en la tierra si, en vez de los dos "ismos" [socialismo liberal y liberalsocialismo (ARM)], se habla de libertad y de igualdad. [...] Pero yo me reconozco mejor, también emotivamente, en el lema: "Giustizia e Libertà"» (1994, p. 59).
} 
artículo de 1989 sobre el ámbito de la democracia, recogido en el capítulo 13 del libro. Es más, cuando en el capítulo 22, de 2005, volví a defender esa misma idea utilicé sin saberlo un argumento similar al de Ferrajoli que yo no conocía (o que no recordaba) y que ahora Vitale trae a colación sin, al parecer, haberse percatado del mío (p. 452): mientras Ferrajoli propone imaginar lo que diría un patricio romano o un señor medieval si le hubieran asegurado que la esclavitud llegaría a ser un delito, yo llamaba a imaginar el salto desde hoy hasta tal Estado mundial apelando a la organización política europea en el siglo X en contraste con la actual Unión Europea (cf. 2020, p. 591).

No acepto, pues, el diagnóstico de Ermanno Vitale de que mi «convicción de fondo reposa en un marco sustancialmente inmutable o, lo que viene a ser lo mismo, sobre el escepticismo respecto de la posibilidad de cambiar el paradigma de las relaciones internacionales» (p. 454). Creo que si el texto se lee sin prejuicios, se puede ver que comparto con Bobbio la filosofía de la historia abierta y liberal también defendida por Kant, este último, al parecer, tan a largo plazo que la fiaba a «una serie de innumerables generaciones», quizá «miles de años» (cit. Pagden, 2013, p. 307). Hoy sabemos que no hay garantía absoluta de que la humanidad disponga de tanto tiempo, pero eso solo confirma la idea kantiana de la apertura de la historia incluso a un mal final. En todo caso, que yo sea escéptico sobre los tiempos breves ha podido dar lugar en otros escritos a manifestar algunas diferencias con el voluntarismo un poco apocalíptico de Ferrajoli (Ruiz Miguel, 2008, pp. 355-367) ${ }^{14}$, quien parece creer en la posibilidad de un cambio cercano, y quizá Vitale se hace eco de esa actitud mía más pesimista, que ha terminado por no dejarme creer en la deliberación sobre cambios inmediatos y radicales que no creo en absoluto posibles. Como recojo en una nota del capítulo, también Bobbio en uno de sus últimos escritos mostró su pesimismo sobre la creación de una fuerza común internacional, y no solo a corto sino «quizá ni siguiera a largo y larguísimo» plazo (2020, p. 592). Lo que no le impidió, como tampoco a mí, defender el «noble ideal» por él mismo propuesto de la edad de los derechos.

Vitale aduce un segundo argumento para mostrar que yo, a diferencia de Ferrajoli, no habría hecho propia ni desarrollado en mi obra la anterior propuesta de Bobbio, que yo, añade, perplejo y aparentemente fascinado ante ella, la admiraría pero sin aceptarla en el fondo (p. 455). Así lo probaría el consecuencialismo ético como criterio más razonable en mis artículos sobre el tema de la guerra recogidos en el libro (pp. 455-456). Tengo que negar la mayor, aunque el discurso deba hacerse aquí algo técnico. Aparentemente, como dice Laporta con alguna cautela en el prólogo al libro, la aparición explícita de la dimensión consecuencialista, de la ética de la responsabilidad, en los capítulos finales del libro contrasta con el predominio de una justificación de tipo deontológico, basada en los derechos humanos, en el resto de los escritos. E intenta explicarlo: "Quizás porque, efectivamente, si se persigue una justicia muy estricta puede caerse el cielo sobre nosotros» (2020, p. 22). Desde luego, mis cautelas ante el eventual deber de intervenir bélicamente en un país como China para defender los derechos humanos (cautelas que Vitale pareció reprocharme en su intervención oral en el seminario de este debate) resultan plenamente justificadas con esa apelación al cielo.

El asunto requeriría un espacio mucho mayor, y habrá que conformarse aquí con una justificación muy somera y, por lo demás, en un asunto tan complejo y del que no me he ocupado nunca de manera profunda sino meramente tentativa. Por indicar sucintamente mis intuiciones básicas, creo que ni un deontologismo

\footnotetext{
14 Hay respuesta de Ferrajoli (2008, pp. 415-418 y 430-433). Sin compartirlas al cien por cien, coincido en varias de las críticas de Pintore (2019, pp. 239-258).
} 
dogmático, sea de deberes como el kantiano o de derechos, ni un consecuencialismo irrestricto pueden servir como marco aceptable de una ética suficientemente convincente. Ambas perspectivas tienen, según yo lo veo, graves puntos ciegos de todos conocidos: desde la inverosímil prohibición de mentir a quien nos pregunta por alguien para asesinarlo por el lado del deontologismo extremo hasta la condena o la tortura de un inocente para salvar a la colectividad por el lado del consecuencialismo irrestricto. En realidad, en un deontologismo de los derechos, muchas veces los conflictos entre ellos no son resolubles sin recurrir a la famosa ponderación, una operación en la que el peso de los fines y la exigencia de proporcionalidad tienden a implicar la comparación de los estados de cosas relevantes y, por tanto, cálculos de consecuencias. Entre uno y otro extremo, la vía maestra puede estar en partir de una posición que postula los derechos básicos y, con ellos, el valor de la autonomía individual como preeminente pero no absoluto, pues también deben garantizarse otros valores como la vida o el bienestar. Tal estructura justificativa podría configurarse como una forma de consecuencialismo pluralista que incluye el valor de la autonomía como preeminente pero no absoluto, es decir, un consecuencialismo ya claramente diferenciado de cualquier forma de monismo valorativo, como el utilitarismo, y que además debería operar como un consecuencialismo de reglas y no de actos y, en fin, evitar el criterio de maximización de los valores asumidos, de modo que pueda mantenerse en lo posible el criterio de separabilidad de las personas que justifica el papel que los derechos básicos cumplen como restricciones a un simple cálculo de consecuencias ${ }^{15}$. En todo caso, mi posición de partida ha sido siempre la defensa de los derechos humanos básicos, que en situaciones extremas y ante conflictos básicos (como entre la vida y la autonomía individual) parecen carecer de respuesta deontologista neta.

Otra vez en una tierra de nadie, podrá replicar Vitale, que a diferencia de Bobbio parece preferir siempre las posiciones netas. Así, cuando yo ilustraba mi posición consecuencialista con la aceptación con alguna reserva de la conocida admonición de El príncipe a no ser bueno entre tantos que no son buenos, el amigo Vitale me recrimina que ya que uso a Maquiavelo no caiga en la contradicción de diluirlo (p. 457). Veo que Vitale comparte así sin rodeos el criterio maquiaveliano de que una vez tomado el mal camino hay que apurarlo hasta el fondo sin escoger nunca "certe vie del mezzo, che sono dannosissime» (Discorsi, I.26). Pero mis reservas solo pretendían, por un lado, restringir la licencia maquiaveliana no a cualquier individuo o príncipe sino a Estados legítimamente organizados y, por otro lado y sobre todo, marcar distancias respecto del pacifismo absoluto ${ }^{16}$. Por lo demás, Ermanno seguro que me permitirá aceptar algunas ideas maquiavelianas sin que eso me comprometa a tener también que suscribir que hay que golpear y castigar a la Fortuna como mujer (Príncipe, XXV) o renunciar a mi bobbiana inclinación a tomar el camino de en medio hasta aplaudir que Giovampagolo Baglioni debería haber asesinado al Papa Julio II haciendo así algo «la cui grandezza avesse superato ogni infamia, ogni pericolo» (Discorsi, I.27).

\footnotetext{
15 Trato de resumir así, de una manera que no puede hacer justicia de la precisión y la riqueza argumentativa, el escrito de Bayón (1989, pp. 461-500), escrito en polémica con Nino (1987). Por lo demás, el tema del constitucionalismo está más desarrollado en Ruiz Miguel (1992, pp. 95-151; del cual es una síntesis el capítulo 20 del libro objeto de estos comentarios).

${ }^{16}$ Recojo aquí el sentido de mi reserva: «la admonición ha de ser debidamente interpretada y corregida en el sentido de que no tiene por qué considerarse por fuerza como una defensa de la política y de la mera efectividad frente a los criterios de corrección ética o moral, siempre que por "ser bueno" se entienda no la única forma de actuar éticamente, sino sólo uno de esos criterios morales propugnados en la historia acaso demasiado excelsos como para que en todos los casos las circunstancias permitan o aconsejen seguirlos: para verlo no hace falta más que sustituir en ese texto las palabras "hombre" y "príncipe" por "Estado". Tal excelsitud inexigible es la que aqueja, a mi modo de ver, al criterio deontológico de que se debe morir antes que matar, típico del pacifismo absoluto» (2020, p. 532).
} 
Si se me permite una comparación hecha con afecto, comprendo que a la Izquierda bobbiana, que Vitale y Ferrajoli bien podrían representar, le parezca censurable mi alejamiento de las posiciones netas y tajantes: en el caso, de un pacifismo absoluto que considera moralmente ilícita sin más toda participación o intervención bélica. Solo puedo replicar que ese alejamiento, mantenido tras haber analizado honestamente los distintos argumentos, es el criterio que considero más fundado. Que Bobbio además, con su gradualismo y su moderantismo, con su

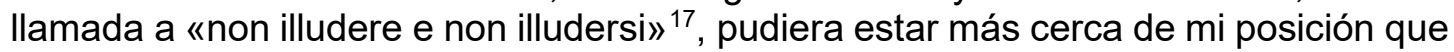
de aquella otra no lo alego como argumento de autoridad, porque creo que yo habría seguido diciendo lo mismo en otro caso, ni tampoco, en absoluto, como reproche por traición alguna al común maestro. Es solo que me parece de justicia reconocerlo.

He dejado para el final las observaciones sobre el último capítulo de mi libro, el dedicado al nacionalismo y al conflicto catalán, sobre el que no creo que esta sea ocasión para entrar en pormenores, pues son muchos y muy complejos los temas mencionados e implicados: de los antecedentes y causas del conflicto a la intervención del 155 a los eventuales y siempre discutibles remedios futuros, de los componentes etnicistas del nacionalismo catalán a su acompañamiento interesado por cálculos económicos o por intereses vétero-revolucionarios, del carácter de golpe inconstitucional del procés a las sanciones penales de sus responsables, de la naturaleza de nuestro Estado autonómico a la posible reforma de la Constitución en un sentido decididamente federal, de la relación de los referendos con la democracia y con la solución del problema catalán a la incomprensión del problema catalán que se refleja en la interpretación de Vitale de un artículo de Félix Ovejero como un ejercicio retórico (p. 461). Me limitaré, pues, a señalar mis discrepancias esenciales con el amigo Vitale tras señalar el, quizá, único acuerdo de fondo en la común aversión hacia el nacionalismo identitario.

Antes de nada, sin embargo, quiero indicar una diferencia que puede parecer menor pero que permite entrar en el núcleo de mi enfoque del problema. El amigo Vitale comienza afirmando que el tema del nacionalismo «es un poco excéntrico» en el apartado en que se sitúa, dedicado a la guerra, la paz y la democracia cosmopolita (p. 458). No lo veo así precisamente porque el nacionalismo me parece el perfecto antagonista del cosmopolitismo. En uno de los buenos intercambios a la hora del café en el Área de Filosofía del Derecho de la UAM (esto fue hace siglos, antes de la pandemia), Juan Carlos Bayón sostuvo que si, ante el caso catalán, se eliminaran todos los factores distorsionantes y fraudulentos del procés -secesión de ricos y «egoísta», riesgo serio para los catalanes no independentistas tras una hipotética sucesión, falta de una mayoría clara, argumentación independentista trufada de engaños y manipulaciones, etc.- él no vería razones éticas para negar la secesión, del mismo modo que admitimos la existencia de las actuales fronteras que dividen a los diferentes Estados. Mi respuesta fue que, incluso en una especie de «situación originaria» perfecta, seguiría habiendo una razón ética para oponerse a la secesión de cualquier región (siempre supuesto, claro está, que el Estado matriz garantice los derechos de la población, incluyendo los derechos a una autonomía regional lealmente practicada): que toda secesión es en principio un paso atrás en el proceso hacia un mundo más integrado y cosmopolita, del mismo modo que la lenta

\footnotetext{
17 Sigo sin encontrar el lugar original de esta frase, que estoy seguro que es de Bobbio. Sobre el moderantismo de Bobbio y su búsqueda de caminos intermedios, además de los escritos citados en la nota 12, puedo recordar aquí cómo, en referencia a su primer escrito político por los años de la Segunda Guerra Mundial, decía sobre él: «in cui seguendo la mia vocazione (si vede viva già allora) di trovare il punto di sintesi fra due estremi dicevo che gli intellettuali dovevano rifuggire da due atteggiamenti altrettanto negativi...» (Bobbio, 1978, p. 53).
} 
superación de las fronteras mediante acuerdos que crean entidades supraestatales tiende a ser un paso adelante ${ }^{18}$.

En la sustancia, la pretensión de mi artículo del 2019 era doble: por un lado, alertar y precaver ante el riesgo de la reviviscencia por reacción de un nacionalismo identitario español que había sido prácticamente sepultado con la Constitución de 1978, porque ese camino no puede llevar más que a la exacerbación irresoluble del problema; y, por otro lado, llamar a la firmeza en la defensa de un modelo constitucional que aliente la lealtad y permita una presencia del Estado común que es normal en cualquier sistema federal y que en España tiende a lo inexistente. Tengo la duda de si Vitale ha captado bien el sentido del primer punto, y me parece que tampoco ha tenido en cuenta que el segundo punto no propone «las condiciones de la rendición» sino mi criterio sobre los términos en los que se debería empezar el diálogo y la negociación, del mismo modo que los independentistas catalanes plantean ahora como punto previo a toda discusión la amnistía y el referéndum de autodeterminación. Como bien ha visto Mauro Barberis en su lectura del capítulo sobre el ámbito de la democracia, y con indudable referencia al tema del referéndum, yo «siempre [he] preferido la negociación desarrollada a nivel constitucional al método democrático aplicado en el nivel local» (pp. 434-435).

Por lo demás, reconozco que mis textos sobre el tema tienen un tono severo que tal vez transpira más pasión que el tono de mis escritos habituales. Es posible que en esas páginas aparezca un «ARM diferente, [...] más propenso a la intransigencia que a la tolerancia» (p. 458), aunque puedo asegurar que mi voluntad de amistad con los amigos de siempre en Cataluña está por encima de esta contingencia. Pero si hay un cambio de tono, ese cambio surge en correspondencia con los desafueros y trapacerías de toda índole del secesionismo y con el gravísimo tensionamiento del sistema democrático español que los responsables políticos secesionistas vienen sosteniendo desde hace algunos años ${ }^{19}$. Como elemento nuevo

\footnotetext{
${ }^{18}$ En un reciente intercambio sobre el tema con Juan Carlos Bayón por correo electrónico, y supuesta la mencionada «situación original», él, aun con dudas, se inclina por seguir manteniendo que si se adopta como criterio central el punto de vista de la justicia distributiva la cuestión es contingente: «un estado independiente puede autoimponerse obligaciones muy exigentes de "justicia global", del mismo modo que un superestado resultante de la fusión de dos o más estados previos podría adoptar políticas redistributivas más regresivas que las que imperaran antes de la fusión en alguna de las unidades que se fusionan». Por mi parte, también dubitativamente, y supuestas siempre las condiciones básicas de la democracia, replicaría que, por un lado, en un proceso de concentración de Estados hacia un Estado cosmopolita tal vez lo más importante e inmediato no es la justicia distributiva sino el progreso hacia un mundo más pacífico (después de todo, no está claro que la Unión Europea haya constituido un avance precisamente en materia de derechos sociales, lo que debe invitar a mejorar en ese ámbito y no a retroceder en el proceso de integración europea); por otro lado, yo tampoco defendería que toda secesión es necesariamente negativa para un proceso cosmopolita, ni que toda integración sea necesariamente positiva), y por ello me he limitado a afirmar la tesis solo «en principio».

${ }_{19}$ Ya pasado un cierto tiempo desde la sentencia del procés, comparto la soberbia reflexión sintética que sobre ella ha hecho Perfecto Andrés Ibáñez los últimos días de febrero, cuando preparo este escrito: «Seguí con enorme preocupación todo lo sucedido y, más o menos, el curso de la causa y del juicio, y leí, pero, sinceramente, no he estudiado, la sentencia. Ahora bien, no eludiré la pregunta y diré que, al margen de las alternativas técnicas en lo relativo a la calificación de las conductas, lo sucedido en Cataluña, en aquellas fechas lamentables, es que unos sujetos públicos recibieron un aparato de poder y lo lanzaron contra el marco constitucional e institucional del que provenía su legitimidad. En el Diccionario de política de Bobbio-Matteucci-Pasquino se recoge una definición de "golpe de estado" tomada del clásico Larousse: "violación deliberada de las formas constitucionales por un gobierno, una asamblea o un grupo de personas que ejercen autoridad". Pues eso. Ya sé que se ha hablado de confrontación de legitimidades y que, en medios de cierta izquierda, hay tendencia a comprender lo sucedido en nombre de no sé qué valores. Incluso en la asociación judicial a la que pertenezco, hubo una ruptura por parte de colegas que participaban de ese insólito criterio. En tales contextos, se ha apelado a la democracia, a cierto mandato popular informal captado por los augures, como modo de dotar de legitimidad a la intentona. La invocada de forma tan gratuita me parece una pintoresca democracia desmelenada, al margen de las reglas, sin cabida en marco constitucional alguno. Esto por
} 
de explicación, puedo alegar aquí que, no sé si con algún exceso de alarma, he vivido estos últimos años con una percepción histórica muy pesimista sobre las graves consecuencias que tendría para España, y quizá para Europa, la separación de Cataluña: a la alta probabilidad de llevarse por delante nuestro sistema democrático se podría sumar una crisis espiritual seguramente todavía más profunda que la del 98, el año de la independencia de Cuba y Filipinas, que deprimió la confianza en el país y anticipó las condiciones para el desastre de la guerra civil.

A propósito del tono, no quiero dejar pasar el comentario de Ermanno a mi respuesta a la intervención del también amigo Luigi Ferrajoli en diciembre de 2019, apenas dos meses después de la sentencia del procés, en favor de una solución de clemencia, una respuesta, dice Vitale, de utonos [...] exacerbados y rígidos en la absoluta seguridad de estar enteramente en la razón» y que a él le sorprendió y amargó personalmente porque yo habría acusado a Ferrajoli con el reproche de falta de coherencia con su propia teoría (p. 460). He releído ese escrito (Ruiz Miguel, 2020a) y no puedo concordar con las anteriores afirmaciones: primero, porque, aunque reproduje el texto en ese sentido de un crítico, yo no suscribí el tono ni la literalidad de tal reproche sino que me limité a defender las principales decisiones judiciales españolas apelando a la cultura constitucionalista compartida con Ferrajoli; $\mathrm{y}$, segundo, porque no empleo ni más ni menos contundencia en la afirmación de mis tesis que la que suele emplear Luigi Ferrajoli en sus textos o, para el caso, de la que emplea el propio Ermanno Vitale en el suyo. Por lo demás, invito a leer despacio y con la debida atención ese escrito mío y otros relacionados con él al menos para desmentir la posible impresión aventada como reproche en el comentario de Vitale de que yo rehúse el diálogo, los instrumentos de la política o la utilización del derecho de gracia ante el conflicto catalán (pp. 459-461) ${ }^{20}$. En todo lo que he escrito sobre el tema, incluida la correspondencia relativamente privada, como en mis conversaciones con los amigos y colegas catalanes, siempre he defendido la necesidad de un diálogo en serio, integrando a todos los interlocutores relevantes y siempre con la mirada puesta en la reconciliación de los propios catalanes.

Por eso no puedo dejar de suscribir las palabras finales del texto de Vitale, extraídas del «Invito al colloquio» con el que Bobbio abrió el diálogo de los primeros años 50 sobre Política e cultura entre la cultura liberal y la comunista (no con la fascista, recuérdese). $Y$ de esas palabras quiero aplicarme ahora la llamada al intelectual a la tarea de sembrar dudas. Oscar Wilde concluyó uno de sus escritos así: «No es que apruebe yo cuanto he dicho en este ensayo. Hay en él cosas con las cuales estoy en completo desacuerdo» (Wilde, 1986, p. 200). Aunque pierda toda su gracia, quiero terminar parafraseando esa humorada diciendo que hay cosas en este escrito de las que quizá no estoy tan seguro como pueda parecer. Pero sí estoy seguro de que no voy a dejar de seguir dando vueltas a las objeciones de los generosos amigos que han participado en este debate.

no hablar del grado de irresponsabilidad y de inepcia de los aprendices de brujo que han sometido a Cataluña y al resto de España a una tensión como la vivida y que se sigue viviendo. Además, para el colmo, en nombre de un pueblo inexistente como tal y bajo la inspiración de un volkgeist que trae los peores recuerdos» (Andrés Ibáñez, 2021).

${ }^{20}$ En particular, en un artículo publicado en esta misma revista hace algo más de dos años, poco antes de la sentencia del procés, yo aceptaba, «según las circunstancias, la posibilidad de una amnistía a los eventuales condenados por los delitos que correspondan en el denominado "procés", siempre que fuera en forma limitada y condicional: limitada, porque en principio debería reducirse a las eventuales penas de prisión antes que a las de inhabilitación y multa; y, en todo caso, condicional, porque debería ser revocable si las personas amnistiadas incumplieran el compromiso de lealtad básica con los mecanismos legales y constitucionales establecidas para los cambios políticos» (Ruiz Miguel, 2018, p. 31, n. 14). Remito también, además de a mis dos escritos sobre el tema ya citados (Ruiz Miguel, 2019 y 2020a), a Ruiz Miguel (2020b). 
Bibliografía

Andrés Ibáñez, P. (2021). Perfecto Andrés Ibáñez: una voz imprescindible. Periferias. Entrevista realizada por Juan García Herrera. Disponible en: https://espacioperiferias.com/2021/02/26/perfecto-andres-ibanez-una-vozimprescindible/ [consultado el 9 de marzo de 2021].

Atienza, M. (2019). Prólogo. En G. Blando, Secularizzazione e laicitá. Practiche argomentative nella CEDU (pp. 19-22). Napoli: Editoriale Scientifica.

Bayón, J.C. (1989). Causalidad, consecuencialismo y deontologismo. Doxa. Cuadernos de Filosofía del Derecho, 6.

DOI: https://doi.org/10.14198/DOXA1989.6.24

Blom, Ph. (2012 [2010]). Gente peligrosa. El radicalismo olvidado de la Ilustración europea. Barcelona: Anagrama. Trad. de D. Najmías.

Bobbio, N. (1955). Política e cultura. Turín: Einaudi.

Bobbio, N. (1976). Quale socialismo? En Quale socialismo. Discussione di un'alternativa. Turín: Einaudi.

Bobbio, N. (1978). II comitato di liberazione della scuola a Torino. En N. Raponi (ed.), Scuola e Resistenza. Parma: La Pilotta Editrice.

Bobbio, N. (1993). Elogio della mitezza. Milán: Línea d'ombra.

Bobbio, N. (1994). Introduzione. Tradizione ed eredità del liberalsocialismo. En M. Bovero, V. Mura y F. Sbarberi, I dilemmi del liberalsocialismo. Roma: La Nuova Italia Scientifica.

Boobio, N. (1994a). Epílogo para españoles. En Á. Llamas (ed.), La figura y el pensamiento de Norberto Bobbio. Madrid: Universidad Carlos III de Madrid-BOE.

Bobbio, N. (1996). Risposta ai critici. En De senectute e altri scritti autobiografici. Turín: Einaudi.

Bobbio, N. (2000). Elogio della mitezza e altri scritti morali. Milán: II Saggiatore.

Conferencia Episcopal Española. (2020). La vida es un don, la eutanasia un fracaso. Nota de la Conferencia Episcopal Española ante la aprobación en el Congreso de los Diputados de la ley de la eutanasia, 11 diciembre. Disponible en: https://www.conferenciaepiscopal.es/interesa/eutanasia/la-vida-es-un-don-laeutanasia-un-fracaso/ [consultado el 9 de marzo de 2021].

Ferrajoli, L. (2008). Principia iuris. Una discusión teórica. Doxa. Cuadernos de Filosofía del Derecho, 31. DOI: https://doi.org/10.14198/DOXA2008.31.26

Flores d'Arcais, P. (2019). Questioni di vita e di norte. Turín: Giulio Einaudi.

Gargarella, R. (1999). Las teorías de la justicia después de Rawls. Un breve manual de filosofía política. Barcelona: Paidós.

Kant, I. (1986 [1793]). En torno al tópico: «Tal vez eso sea correcto en teoría, pero no sirve para la práctica». En R. R. Aramayo (ed.), Teoría y práctica. Madrid: Tecnos.

Leni, F. (2016). Liberal Neutrality and State Support for Religion. Cham: Springer.

Merrill, R. y Weinstock, D. (eds.) (2014). Political Neutrality. A Re-evaluation. Nueva York: Palgrave Macmillan.

Nino, C.S. (1987). El cuatrilema del consecuencialismo. Doxa. Cuadernos de Filosofía del Derecho, 4. DOI: https://doi.org/10.14198/DOXA1987.4.23

Pagden, A. (2013). The Enlightenment and Why it Still Matters. Oxford: Oxford University Press.

Perelman, Ch. (1964 [1945]). De la justicia. México: Universidad Nacional Autónoma de México. Trad. de R. Guerra.

Pintore, A. (2019). Disuguaglianze e apocalisse. Sul Manifesto di Luigi Ferrajoli. Diritto \& Questioni Pubbliche, XIX/2.

Queralt, J. (2014). Igualdad, suerte y justicia. Madrid: Marcial Pons.

Rawls, J. (1999). A Theory of Justice Cambridge: Harvard University Press, $2^{\mathrm{a}}$ ed.

Rousseau, J.J. (1959). Les confessions. En B. Gagnebin y M. Raymond (eds.), Oeuvres complètes, I. París: Gallimard. 
Ruiz Miguel, A. (1992). Guerras justas e injustas: entre la moral y el Derecho. En Cursos de Derecho Internacional de Vitoria-Gasteiz 1991. Bilbao: Servicio Editorial de la Universidad del País Vasco.

Ruiz Miguel, A. (1994). Bobbio: las paradojas de un pensamiento en tensión. En Á. Llamas (ed.), La figura y el pensamiento de Norberto Bobbio. Madrid: Universidad Carlos III de Madrid-BOE.

Ruiz Miguel, A. (2000). Política, Historia y Derecho en Norberto Bobbio. México: Fontamara, $2^{\mathrm{a}}$ ed.

Ruiz Miguel, A. (2002). Concepciones de la igualdad y justicia distributiva. En E. Díaz y J.L. Colomer (eds.), Estado, justicia, derechos. Madrid: Alianza.

Ruiz Miguel, A. (2003). Costituzionalismo e democrazia. Teoria politica, XIX/2-3. Trad. italiana de Valentina Pazé (en versión castellana y reducida: Id. (2004). Constitucionalismo y democracia. Isonomía. Revista de Teoría y Filosofía del Derecho, 21).

Ruiz Miguel, A. (2005). Azar, igualdad y biotecnología. En A. Jorge Barreiro (ed.), Homenaje al Profesor Dr. Gonzalo Rodríguez Mourullo. Madrid: Thomson-Civitas.

Ruiz Miguel, A. (2005a). Azar, biotecnología y justicia sanitaria. En Bioética, religión y Derecho. Madrid: Fundación Universitaria Española, 2005.

Ruiz Miguel, A. (2008). Valores y problemas de la democracia constitucional cosmopolita. Doxa. Cuadernos de Filosofía del Derecho, 31. DOI: https://doi.org/10.14198/DOXA2008.31.23

Ruiz Miguel, A. (2010). La laicidad y el eterno retorno de la religión. En R. Vázquez, A. Ruiz Miguel y J.M. Vilajosana Rubio, Democracia, religión y Constitución. Madrid: Fundación Coloquio Jurídico Europeo.

Ruiz Miguel, A. (2016). Crisis institucional, partidos y democracia representativa. En R.R. Aramayo, J.F. Álvarez, F. Maseda y C. Roldán (eds.), Diálogos con Javier Muguerza. Paisajes para una exposición virtual (Un homenaje de Isegoría por su 80 cumpleaños). Madrid: Consejo Superior de Investigaciones Científicas.

Ruiz Miguel, A. (2018). Gracia y justicia: el lugar de la utilidad pública. Eunomía. Revista en Cultura de la Legalidad, 15.

DOI: https://doi.org/10.20318/eunomia.2018.4340

Ruiz Miguel, A. (2019). Sobre desobediencia, amistad y lealtad. Jueces para la democracia. Información y debate, 96.

Ruiz Miguel, A. (2020). Cuestiones de principios: entre política y Derecho. Madrid: Centro de Estudios Políticos y Constitucionales.

Ruiz Miguel, A. (2020a). Luigi Ferrajoli y Cataluña: una correspondencia. En Almacén de Derecho, 2 de enero. Disponible en: https://almacendederecho.org/luigiferrajoli-y-cataluna-una-correspondencia [consultado el 9 de marzo de 2021].

Ruiz Miguel, A. (2020b). Más sobre Cataluña: carta a J.J. Moreso. Almacén de Derecho, 11 de enero. Disponible en: https://almacendederecho.org/mascorrespondencia-sobre-cataluna-carta-a-j-i-moreso [consultado el 9 de marzo de 2021].

Ruiz Miguel, A. (2021). Laicidad liberal y laicismo. Doxa. Cuadernos de Filosofía del Derecho [próxima publicación en el número 44].

Varios. (1964). Filosofia come metodologia o filosofia come visione del mondo? La Cultura, II.

Voltaire. (1986). La princesa de Babilonia. En J.L. Borges (ed.), Micromegas. Madrid: Siruela.

Westen, P. (1981). The Empty Idea of Equality. Harvard Law Review, 95/3.

Westen, P. (1990). Speaking of Equality. An Analysis of the Rhetorical Force of "Equality» in Moral an Legal Discourse. Princeton: Princeton University Press.

Wilde, O. (1986). La verdad de las máscaras. En Ensayos. Artículos. Barcelona: Orbis. Trad. de J. Gómez de la Serna y prólogo de J.L. Borges.

Zellentin, A. (2012). Liberal Neutrality: Treating Citizens as Free and Equal. BerlínBoston: De Gruyter. 